\title{
Author Correction to: The transgluteal approach to shockwave lithotripsy to treat distal ureter stones: a prospective, randomized, and multicenter study
}

Min Soo Choo ${ }^{1} \cdot$ Jun Hyun Han ${ }^{1} \cdot$ Jong Keun Kim ${ }^{1} \cdot$ Tae Young Shin $^{2} \cdot$ Won Ki Lee ${ }^{2} \cdot$ Sang Kon Lee $^{2} \cdot$ Seong Ho Lee $^{1}$ D

Published online: 11 April 2018

๑) Springer-Verlag GmbH Germany, part of Springer Nature 2018

Author Correction to: World Journal of Urology https://doi.org/10.1007/s00345-018-2244-4

The funding number was incorrect in the original published article. The correct funding number should read as follows:

Funding This research was supported by Hallym University Research Fund 2014 (HURF-2014-57).

The original article can be found online at https://doi.org/10.1007/ s00345-018-2244-4.

Seong Ho Lee

shleeuro@hallym.ac.kr

1 Department of Urology, Hallym University Songtan Sacred Heart Hospital, Hwaseong, Korea

2 Department of Urology, Hallym University Chuncheon Sacred Heart Hospital, Chuncheon, Korea 